\title{
Relation between Body Mass Index, Waist Circumference, and Echocardiographic Index of Left Ventricular Diastolic Function (Korean J Obes 2016;25:84-91)
}

\author{
Ji A Seo* \\ Division of Endocrinology and Metabolism, Department of Internal Medicine, Korea University Ansan Hospital, Ansan, Korea
}

Obesity is well known as an independent predictor of incident heart failure in the general population. ${ }^{1}$ Overweight subjects also have an increased risk of heart failure. ${ }^{2}$ The excess in body fat induces chronic volume overload due to hyperdynamic circulation and directly affects cardiac structure and function, including having a negative impact on both systolic and diastolic left ventricular (LV) function. ${ }^{3}$ Moreover, other major risk factors for heart failure, including hypertension and coronary heart disease, are more prevalent in obese subjects than lean subjects.

Cho et al. ${ }^{4}$ investigated the association of obesity with diastolic dysfunction in Korean adults from a health screening program of one hospital. They excluded subjects with systolic LV dysfunction, structural heart disease, hypertension, diabetes, dyslipidemia, renal dysfunction and thyroid disease, which could affect LV diastolic function. Therefore, the study subjects were healthy, middle aged Koreans and their average values of parameters for $\mathrm{LV}$ function were in the normal range. Nevertheless, this study showed a certain trend for worsening LV diastolic function in obesity, suggesting a graded response between body size and LV diastolic dysfunction. They investigated whether the severity of obesity was independently associated with LV diastolic dysfunction using body mass index or waist circumference as obesity indices, respectively. Both body mass index and waist circumference were positively associated with worsening LV diastolic function similarly. Although they tried to investigate gender difference, the number of women subjects was too small to show a reliable conclusion.

There have been numerous studies about LV diastolic dysfunction in obesity. ${ }^{3-9}$ In Koreans, very recently, Son et al. reported the association between abdominal obesity and geometric and functional changes of the heart in 1,460 healthy Korean males from a population-based cohort. ${ }^{10}$ They showed that waist circumference had stronger associations with left atrial enlargement, LV enlargement, and LV diastolic dysfunction (using different parameters from Cho et al.'s $\mathrm{E} / \mathrm{E}$ ') than body mass index. It is not known if any other parameters for cardiac function except $\mathrm{E} / \mathrm{E}$ ' were associated with central obesity, independent of the covariates in Cho's study population. In addition, the estimation of associations between central obesity and markers of cardiac function in each body mass index category could be assessed, although the number of study subjects was small.

Meanwhile, recent evidence has documented an 'obesity paradox' in large cohorts with heart failure, where overweight and obese patients (not severe obese) have a better prognosis, at least in short-term follow-up studies, compared with lean heart failure patients. ${ }^{1,11,12}$ The mechanisms for the obesity paradox in heart failure are unclear, but potential reasons include less cachexia, protective cytokines from fat, and a larger amount of lean muscle mass in obese subjects. ${ }^{6}$ Because there are no large clinical studies on the role of weight loss in preventing clinical events in heart failure, there are no definitive guidelines on optimal body composition in patients with heart failure, especially in less severely obese and overweight patients. Considering
*Corresponding author Ji A Seo (iD http://orcid.org/0000-0002-1927-2618 Division of Endocrinology and Metabolism, Department of Internal Medicine, Korea University Ansan Hospital, 123 Jeokgeum-ro, Danwon-gu, Ansan 15355, Korea Tel: +82-31-412-4275 Fax: +82-31-412-5984 E-mail: seo-ji-a@hanmail.net
Copyright () 2016 Korean Society for the Study of Obesity

(c) This is an Open Access article distributed under the terms of the Creative Commons Attribution Non-Commercial License (http://creativecommons.org/licenses/by-nc/4.0/) which permits unrestricted non-commercial use, distribution, and reproduction in any medium, provided the original work is properly cited. 
that substantial weight loss from diet or bariatric surgery can reverse many of the alterations in cardiac performance and morphology associated with obesity, future prospective studies are important to elucidate the effects of intentional weight loss on prognosis of heart failure.

\section{Conflicts of Interest}

I have no conflicts of interest.

\section{References}

1. Kenchaiah S, Evans JC, Levy D, Wilson PW, Benjamin EJ, Larson MG, et al. Obesity and the risk of heart failure. N Engl J Med 2002; 347:305-13.

2. Loehr LR, Rosamond WD, Poole C, McNeill AM, Chang PP, Folsom AR, et al. Association of multiple anthropometrics of overweight and obesity with incident heart failure: the atherosclerosis risk in communities study. Circ Heart Fail 2009;2:18-24.

3. Alpert MA, Lavie CJ, Agrawal H, Kumar A, Kumar SA. Cardiac effects of obesity: pathophysiologic, clinical, and prognostic consequences-a review. J Cardiopulm Rehabil Prev 2016;36:1-11.

4. Cho YJ, Lee GH. Relation between body mass index, waist circumference, and echocardiographic index of left ventricular diastolic function. Korean J Obes 2016;25:84-91.
5. Alpert MA, Omran J, Mehra A, Ardhanari S. Impact of obesity and weight loss on cardiac performance and morphology in adults. Prog Cardiovasc Dis 2014;56:391-400.

6. Lavie CJ, Alpert MA, Arena R, Mehra MR, Milani RV, Ventura HO. Impact of obesity and the obesity paradox on prevalence and prognosis in heart failure. JACC Heart Fail 2013;1:93-102.

7. Lavie CJ, Amodeo C, Ventura HO, Messerli FH. Left atrial abnormalities indicating diastolic ventricular dysfunction in cardiopathy of obesity. Chest 1987;92:1042-6.

8. Lavie CJ, Patel DA, Milani RV, Ventura HO, Shah S, Gilliland Y. Impact of echocardiographic left ventricular geometry on clinical prognosis. Prog Cardiovasc Dis 2014;57:3-9.

9. Pascual Díaz M, Tébar Massó FJ, Hernández Martínez AM, Pomares Gómez F, Vicente Vera T, Soria Arcos F, et al. Effect of obesity on the morphology of the left ventricle. Med Clin (Barc) 1999;113:721-5.

10. Son JW, Sung JK, Lee JW, Youn YJ, Ahn MS, Ahn SG, et al. Abdominal obesity and structure and function of the heart in healthy male Koreans: the arirang study. Medicine (Baltimore) 2016;95: e4930.

11. Lavie CJ, Ventura HO. The obesity paradox in heart failure: is it all about fitness, fat, or sex? JACC Heart Fail 2015;3:927-30.

12. Vest AR, Wu Y, Hachamovitch R, Young JB, Cho L. The heart failure overweight/obesity survival paradox: the missing sex link. JACC Heart Fail 2015;3:917-26. 